\title{
Palm oil as a renewable raw material in the synthesis of new polymeric materials through the epoxy fusion process
}

\author{
A. Sienkiewicz, P. Czub* , A. Milo \\ Department of Chemistry and Technology of Polymers, Faculty of Chemical Engineering and Technology, Cracow \\ University of Technology, Warszawska Str. 24, Kraków, Poland
}

Received 2 October 2020; accepted in revised form 10 December 2020

\begin{abstract}
The presented research shows the results of the investigations on the synthesis of polymeric materials through the fusion reaction of modified palm oil derivatives. First, raw palm oil was subjected to epoxidation. In order to determine the best reaction conditions, the process was conducted under four different conditions. In the next stage, the polyaddition products were obtained by the reaction of epoxidized palm oil (EOP) and bisphenol A (BPA), through the epoxy fusion process. On the basis of the performed studies, using both analysis of the content of functional groups, as well as data obtained from FT-IR, GPC, ${ }^{1} \mathrm{H}$ NMR and ${ }^{13} \mathrm{C}$ NMR analyses of the chemical structure of all obtained palm oil derivatives was determined. It was found that during the polyaddition process, after the reaction of the oxirane group of EOP with the hydroxyl group of BPA, a subsequent reaction occurred, involving the reaction of a free phenolic group with the following macromolecule of modified oil. Finally, obtained bio-polyaddition products were used: (1) to obtain 'stand-alone' epoxy-polyurethane materials and (2) as modifiers of a commercial bisphenol A-based low molecular weight epoxy resin.
\end{abstract}

Keywords: biopolymers, epoxidized palm oil, epoxy resin, epoxy fusion process, mechanical properties

\section{Introduction}

The variable economic situation and, especially in recent years, ecological and social considerations are the main reason for the great interest in natural materials, preferably from renewable sources. They could potentially replace petrochemical raw materials used, among others, for the synthesis and modification of polymers [1]. Among natural origin materials, plant oils and especially vegetable oils are one of the most important groups. They are nontoxic, cheap, and their chemical structure allows for chemical modification, usually quite simple towards the specific applications [2,3]. Vegetable oils are one of the most rapidly expanding agricultural sectors. Their worldwide availability and relatively low prices make them industrially attractive and feasible. The largest sources of vegetable oils are plants, such as soybean, corn, rapeseed, linseed, cottonseed, peanuts, palm, and olive [4]. Global palm oil production is increasing by $9 \%$ every year [5]. By 2050 demand is estimated to be 240 million tons per year, which is approximately twice the amount produced in 2009 $[6,7]$. Palm oil is widely used, primarily in the food and cosmetics industries. However, it is also an interesting raw material for the plastics industry, and it is used as plasticizer for poly(vinyl chloride) [8], polyol $[9,10]$ or palm oil-based epoxidized diethanolamides [11] for the synthesis of polyurethane materials, a raw material for the preparation of UV-curable polyacrylates $[12,13]$, polyesters [14] and as a component of the composition of cycloaliphatic epoxy resins $[15,16]$. Taking into consideration the emerging controversy regarding the negative effects of palm oil on human health and the environment [17-20], it seems desirable to search for new possibilities of using palm oil, as e.g. a raw material for the synthesis

${ }^{*}$ Corresponding author, e-mail: pczub@pk.edu.pl

(C) BME-PT 
of polymeric materials. Especially that palm oil is produced on a large scale in many countries around the world [6]. Crude palm oil contains about: $41.8 \%$ of palmitic $\left(\mathrm{C}_{16: 0}\right), 3.4 \%$ of stearic $\left(\mathrm{C}_{18: 0}\right), 41,9 \%$ of oleic $\left(\mathrm{C}_{18: 1}\right)$, and $11.0 \%$ of linoleic $\left(\mathrm{C}_{18: 2}\right)$ fatty acids [21]. One of the interesting features of palm oil, among the most commonly used vegetable oils, is the relatively low average content of unsaturated bonds per triglyceride molecule (about 1.8). It means that if the modification of such triglyceride or reaction using it as a substrate occurs through an unsaturated bond [22], it behaves as a difunctional compound. The average functionality of most vegetable oils used in practice for the modification or the synthesis of polymers is several times higher (e.g. 3.8 for rapeseed oil, 4.6 for soybean and sunflower oils, and 6.6 for linseed oil). The use of modified vegetable oils as reagents with greater functionality leads to the production of branched or even crosslinked products.

We decided to apply palm oil and its derivatives for the modification of epoxy resin networks. First [23], we examined the possibility of using epoxidized palm oil as a modifier of bisphenol A-based epoxy resins. The main purpose of conducted studies was the elimination or at least reduction of the influence of the rigid structure of bisphenol-based epoxy materials on their performance properties. The epoxidized palm oil was synthesized and pre-polymerized in a reaction with isophorone diamine, and next, the resulting palm oil derivatives were used as modifiers of a bisphenol A-based low molecular weight epoxy resin. The prepared compositions and the pure, unmodified epoxy resin were cured with isophorone diamine, and then their mechanical properties (i.e., tensile, flexural, and compressive strengths, hardness and impact strength), thermal properties (using DMA) and morphology (by SEM) were examined. Unfortunately, in addition to the desired effects such as the increase of the flexibility and the impact strength (even twice) of obtained epoxy material, usually the addition of epoxidized palm oil to the resin caused a deterioration of other mechanical parameters. The research presented within this manuscript was focused on further studies on palm oil derivatives. Here, the epoxidized palm oil was used together with bisphenol A to obtain polyaddition products via the epoxy fusion process. These bio-polyaddition products were next used: (1) to obtain 'stand-alone' epoxypolyurethane materials and (2) as modifiers of a commercial bisphenol A-based low molecular weight epoxy resin. As it was mention before in our previous research papers $[24,25]$, the epoxy fusion process is known as the reaction between bisphenols and lowor average-molecular weight (1500-10000 g/mol) epoxy resins, which is conducted in bulk, at a temperature higher than the melting temperature of the raw materials, in the presence of catalysts (such as inorganic bases, tertiary amines, quaternary ammonium salts, phosphines, hydroxyamines, or imidazoles), and an inert atmosphere, without the addition of solvents or diluents. Based on the results of performed studies, it was found that modified vegetable oils (epoxidized or hydroxylated) can successfully partially replace petrochemical resources. In other words, epoxidized oils can be used in a place of low and average molecular weight epoxy resins, while hydroxylated ones can substitute for bisphenol A (BPA) in the conventional method of epoxy resins synthesis. It is worth noting that vegetable oils provide better flexibility and a wider range of available crosslinking agents (including both: typically used for epoxy resins, amines or acidic anhydrides, and isocyanates, which are usually applied in the polyurethanes technology) for promising novel bio-based polymer materials. Due to its functionality close to 2 , palm oil is successfully suitable as a reagent in the epoxy fusion process because it allows obtaining the desired products with a higher molecular weight and linear structure.

\section{Materials and methods}

\subsection{Epoxidation of palm oil}

Epoxidation of palm oil (PPUH 'ELIOT', Poland, $I V=50.82 \mathrm{~g} I_{2} / 100 \mathrm{~g}$ ), in general, was carried out in the system hydrogen peroxide/acetic acid/sulphuric acid (POCh S.A., Poland, pure; $0.5 \mathrm{~mol}$ of acid, $1.5 \mathrm{~mol}$ of $\mathrm{H}_{2} \mathrm{O}_{2}$ and $0.03 \%$ of $\mathrm{H}_{2} \mathrm{SO}_{4}$ per $1 \mathrm{~mol}$ of unsaturated bonds in oil). Reaction mixture consisting of $1000 \mathrm{~g}$ of palm oil $\left(I V=50.82 \mathrm{~g} I_{2} / 100 \mathrm{~g}\right.$, which is 2.005 moles of unsaturated bonds), $57 \mathrm{ml}$ $(0.5 \mathrm{~mol})$ of glacial acetic acid, $3.4 \mathrm{ml}(0.03 \mathrm{~mol})$ of sulfuric acid and $150 \mathrm{ml}$ of toluene was heated up to $55^{\circ} \mathrm{C}$ while stirring, $307 \mathrm{ml}(1.5 \mathrm{~mol})$ of $\mathrm{H}_{2} \mathrm{O}_{2}$ was added dropwise within 1 hour. The epoxidation of palm oil, as shown in Table 1, was conducted under four different conditions of the process.

\subsection{Epoxy fusion process}

Epoxidized palm oil, bisphenol A (BPA, GE Cartagenie, Spain, 99.93\%), and lithium chloride $(\mathrm{LiCl}$, 
Table 1. Epoxidation of palm oil - reaction conditions.

\begin{tabular}{|c|c|c|c|c|c|}
\hline \multirow{2}{*}{ Reaction conditions } & & \multicolumn{4}{|c|}{ Epoxidized palm oil } \\
\hline & & EOP-1 & EOP-2 & EOP-3 & EOP-4 \\
\hline Addition of solvent & & + & - & - & + \\
\hline Time of conducting the process & {$[\mathrm{h}]$} & 6 & 24 & 12 & 6 \\
\hline Temperature of the $\mathrm{I}^{\text {st }}$ stage of the process ${ }^{\mathrm{a}}$ & {$\left[{ }^{\circ} \mathrm{C}\right]$} & 55 & 55 & 55 & 55 \\
\hline Temperature of the II ${ }^{\text {nd }}$ stage of the process ${ }^{b}$ & {$\left[{ }^{\circ} \mathrm{C}\right]$} & $60-65$ & $60-65$ & $60-65$ & $54-55$ \\
\hline
\end{tabular}

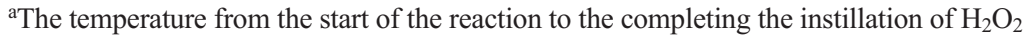

${ }^{\mathrm{b}} \mathrm{The}$ temperature after the instillation of $\mathrm{H}_{2} \mathrm{O}_{2}$

Merck, Germany, pure; in the amount of $0.002 \mathrm{~mol}$ per $1 \mathrm{~mol}$ of $\mathrm{OH}$ groups) were involved in the fusion reaction. The process was carried out in the nitrogen atmosphere, using different amount of BPA calculated based on Equation (1):

$\frac{m_{\mathrm{BPA}}}{m_{\mathrm{EOP}}}=\frac{M_{\mathrm{BPA}} \cdot\left(E V_{\mathrm{EOP}}-E V_{\mathrm{EOP}_{2} \mathrm{BPA}}\right)}{M_{\mathrm{BPA}} \cdot E V_{\mathrm{EOP}_{-} \mathrm{BPA}_{1}}+200}$

where $m_{\mathrm{BPA}}-$ amount of bisphenol A, $m_{\mathrm{EOP}}-$ amount of epoxidized palm oil, $E V_{\mathrm{EOP}}$ - epoxy value of epoxidized palm oil, $E V_{\text {EOP_BPA }}$ - estimated epoxy value of product of epoxidized palm oil and bisphenol and $M_{\mathrm{BPA}}$ - molar mass of BPA) describing the change of the quantity of functional groups in the reactants and products during the reaction, which included the assumption that the obtained product should have $E V \approx 0.100 \mathrm{~mol} / 100 \mathrm{~g}$ or (2) equimolar ratio of hydroxyl groups of bisphenol and epoxy groups of modified palm oil (Table 2).

The reaction mixture of epoxidized palm oil and BPA was homogenized, followed by adding the $\mathrm{LiCl}$ and raised to the desired temperature of $160^{\circ} \mathrm{C}$. The duration of the process was established experimentally by monitoring the epoxy value of the reacting mixture [26].

\subsection{Iodine, epoxy, and hydroxyl values of palm oil}

Iodine, epoxy, and hydroxyl values of palm oil and its derivatives were evaluated according to standards.

Table 2. The amount of reagents used in the polyaddition reaction.

\begin{tabular}{|l|c|c|}
\hline \multirow{3}{*}{ Reagents } & \multicolumn{2}{|c|}{$\begin{array}{c}\text { Weight of reagents used to obtain polyaddition } \\
\text { product of epoxidized palm oil and bisphenol A }\end{array}$} \\
\cline { 2 - 3 } & $\begin{array}{r}\text { EOP_BPA(1) } \\
\text { [g] }\end{array}$ & $\begin{array}{c}\text { EOP_BPA(2) } \\
\text { [g] }\end{array}$ \\
\hline EOP & 100.0 & 100.0 \\
\hline BPA & 7.27 & 19.52 \\
\hline LiCl & 0.003 & 0.007 \\
\hline
\end{tabular}

Iodine value $(I V)$, describing the content of unsaturated bonds, was determined with the Hanus method according to PN-EN ISO 3961:2011 standard. The iodine number was calculated according to Equation (2):

$$
\begin{aligned}
I V & =\frac{\left(V_{1}-V_{2}\right) \cdot 0.01269 \cdot 100}{m}= \\
& =\frac{\left(V_{1}-V_{2}\right) \cdot 1.269}{m} \quad\left[\mathrm{~g} I_{2} / 100 \mathrm{~g}\right]
\end{aligned}
$$

where $V_{1}$ - the volume of sodium thiosulfate solution at concentration $c=0.1 \mathrm{~mol} / 1$ used for blank titration [ml], $V_{2}$ - the volume of sodium thiosulfate solution at concentration $c=0.1 \mathrm{~mol} / 1$ used to titrate the sample [ml], $m$ - weight of the sample [g], 0.01269 - amount $[\mathrm{g}]$ of iodine corresponding to $1 \mathrm{ml}$ of sodium thiosulfate solution at concentration $c=0.1 \mathrm{~mol} / 1$.

Samples of products were dissolved in chloroform, where iodine bromide in glacial acetic acid was added, and the prepared solution was titrated with sodium thiosulfate in the presence of aqueous starch solution to the moment of its discoloration.

Content of epoxy groups (epoxy value, $E V$ ) in the investigated products was evaluated according to PN-87/C-89085/13 standard: samples were dissolved in $\mathrm{HCl} / 1$,4-dioxane solution and titrated by $\mathrm{NaOH} /$ methanol in the presence of cresol red as an indicator until the tint changed to purple. The epoxy value was calculated according to Equation (3):

$E V=\frac{\left(V_{1}-V_{2}\right) \cdot c_{\mathrm{NaOH}} \cdot 100}{m \cdot 1000}[\mathrm{~mol} / 100 \mathrm{~g}]$

where $V_{1}$ - the volume of the $\mathrm{NaOH}$ alcohol solution used in the blank titration [ml], $V_{2}$ - the volume of the $\mathrm{NaOH}$ alcohol solution used to titrate the sample [ml], $m$-weight of the sample [g], $c_{\mathrm{NaOH}}$ - the concentration of the alcoholic $\mathrm{NaOH}$ solution [mol/l]. In order to define the hydroxyl value $(H V)$, samples of palm oil, its epoxidized and fusion derivatives were dissolved in the solution of the catalyst 
[4(dimethylamino)pyridine in DMF] and acetic anhydride in DMF. Followed by intensive stirring for another 15 min and titration with $\mathrm{KOH}$ aqueous solution in the presence of thymolphthalein until the tint changed from colorless to blue. The hydroxyl number was calculated from Equation (4):

$$
H V=\frac{\left(V_{1}-V_{2}\right) \cdot 56.1 \cdot c_{\mathrm{KOH}}}{m}+A V[\mathrm{mg} \mathrm{KOH} / \mathrm{g}]
$$

where $V_{1}$ - the volume of the aqueous $\mathrm{KOH}$ solution at concentration $c_{\mathrm{KOH}}=0.1 \mathrm{~mol} / \mathrm{l}$ used for the blank titration [ml], $V_{2}-$ the volume of the aqueous $\mathrm{KOH}$ solution at concentration $c_{\mathrm{KOH}}=0.1 \mathrm{~mol} / 1$ used to titrate the sample [ml], 56.1 - the number of milligrams of $\mathrm{KOH}$ corresponding to $1 \mathrm{ml}$ of $\mathrm{KOH}$ solution at concentration $c_{\mathrm{KOH}}=0.1 \mathrm{~mol} / 1, m$ - weight of the sample [g], $A V$ - acid value of the sample $[\mathrm{mg} \mathrm{KOH} / \mathrm{g}]$.

\subsection{Spectroscopic measurements}

The analysis of transmittance FT-IR spectroscopy was achieved using an FT-IR PerkinElmer precisely system spectrophotometer (SPECTRUM 65 FT-IR, PerkinElmer, UK) with ATR adapter. The analyzes were carried out at room temperature. Spectra were recorded for a wave number in the range of 4000 $600 \mathrm{~cm}^{-1}$. Obtain spectra are presented in the dependence of transmittance $T[\%]$ and wavenumber $v\left[\mathrm{~cm}^{-1}\right]$.

\subsection{Gel permeation chromatography}

The number-average molecular weight $\left(\bar{M}_{\mathrm{w}}\right)$, weightaverage molecular weight $\left(\bar{M}_{\mathrm{w}}\right)$, and polydispersity index $\left(P I, P I=\bar{M}_{\mathrm{w}} / \bar{M}_{\mathrm{n}}\right)$ of obtained products were determined by Knauer Gel-permeation chromatography (Germany) with two PL-Gel columns (300× $7.5 \mathrm{~mm}$ ) with grain size $3 \mu \mathrm{m}$ and MIXED-E pores, and a refractive index detector. The equipment was calibrated using standard polystyrene samples in the molecular weight range of 410 to $20500 \mathrm{~g} / \mathrm{mol}$. The analyses were performed at $25^{\circ} \mathrm{C}$, and the tetrahydrofuran dried over metallic sodium, distilled, and stabilized with BHT (2,6-bis(1,1-dimethylethyl)-4 methylphenol, Sigma-Aldrich, USA) was used as an eluent (with eluent flow $0.8 \mathrm{ml} / \mathrm{min}$ ).

\section{6. ${ }^{1} \mathrm{H}$ NMR and ${ }^{13} \mathrm{C}$ NMR analysis}

One-dimensional ${ }^{1} \mathrm{H}$ NMR and ${ }^{13} \mathrm{C}$ NMR spectra were recorded using a $600 \mathrm{MHz}$ NMR Avance III apparatus (Bruker, UK) at room temperature and using deuterated acetone as the solvent. The obtained spectra were processed using the MestReNova software.

\subsection{Mechanical properties}

The mechanical properties of the prepared composition were tested on samples in the forms of paddles, beams, and rollers. The tensile strength, elongation at break, modulus elasticity, flexural strength, elasticity flexural modulus, deflection, compressive strength, and compression set were tested on the Zwick 1445 apparatus (Poland). The tensile strength, elongation at break, modulus elasticity were determined according to PN-EN ISO 527-1:2012 standard on samples in the form of paddles (type B) [section measurement with dimensions: $4 \times 10$ (at crosssection) and $50 \mathrm{~mm}$ (length)] and using the Zwick apparatus equipped with an extensometer. Measurements were conducted at $5 \mathrm{~mm} / \mathrm{min}$ testing speed. Flexural strength, elasticity, flexural modulus, deflection were tested according to PN-EN ISO 178:2011 standard: samples were in the form of cuboids' beams with the cross-section dimensions of $4 \times 10 \mathrm{~mm}$, $64 \mathrm{~mm}$ spacing between supports, and a testing speed of $10 \mathrm{~mm} / \mathrm{min}$. Compressive strength and compression set were tested according to PN-EN ISO 604:2006 standard: samples were in the form of rollers with $10 \mathrm{~mm}$ diameter and $25 \mathrm{~mm}$ height with the testing speed of $0.8 \mathrm{~mm} / \mathrm{min}$. Hardness in Shore's A scale was tested according to PN-EN ISO 868:2005 standard with the use of the InSize apparatus. Impact strength without notched by the Charpy's method PN-EN ISO 179-2:2001 was tested on the ZORN PSW 4J Digital apparatus, using cuboids' beams with the cross-section dimensions $4 \times 10 \mathrm{~mm}$.

\section{Results and discussion}

\subsection{Modification of palm oil and products characteristics}

The epoxidation process of unsaturated bonds of palm oil was conducted by vegetable oil modification, called the Prilezaev method. The reaction was carried out in the system: acetic acid/hydrogen peroxide in the presence of sulfuric acid(VI) as a catalyst (Figure 1). However, the actual oxidizing agent of this reaction was the organic peracid, formed in situ in the reaction of acetic acid with hydrogen peroxide. The newly formed organic peracid reacts with unsaturated bonds of palm oil. We conducted the epoxidation of palm oil under four variants of the process (Table 1). Differences between reactions 


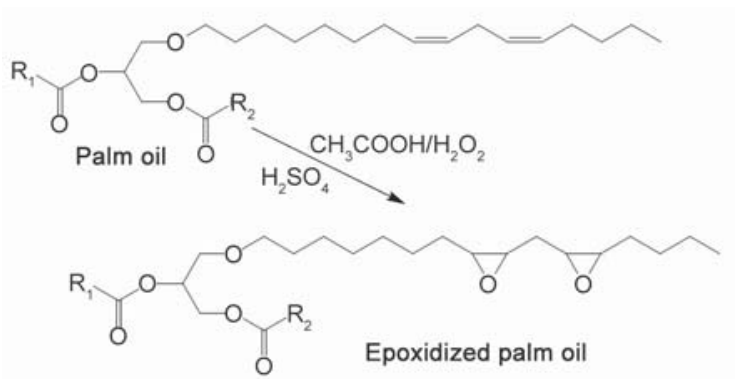

Figure 1. Epoxidation of vegetable oil by Prilezaev method.

were related to (1) the use of a solvent in the reaction system, (2) the time of conducting the epoxidation, and (3) the temperature of the second stage of the process. During the modification process, especially in the case of triglycerides, which are characterized by relatively low functionality, it is extremely important to choose the proper reaction conditions, which are leading to the limitation to the greatest extent undesirable side reactions, as well as increased efficiency of the process. The presence of strong mineral acids in the environment favors the occurrence of unfavorable side reactions resulting in the opening of oxirane rings and creating, e.g. diols and hydroxyesters [27]. According to studies conducted, e.g. by Chua [28], the course of the epoxidation reaction is closely related to the choice of carboxylic acid, the type and concentration of the catalyst in the system, temperature, stirring speed, and the type of used solvent [29]. That is why in our research, keeping in mind the previous studies on the epoxidation process, we decided to carry out an epoxidation reaction: without the solvent (acronyms EOP-2 and EOP-3 represent processes, where palm oil itself was the organic phase of the reaction), in relatively mild temperature conditions of the second stage of the reaction (EOP-4) or in a shorter time of conducting the process (EOP-1 and EOP-4). Throughout such operations, we were trying to achieve the highest efficiency of the process and decrease undesired side reactions.

The chemical structures of commercial palm oil and obtained palm oil derivatives were evaluated by the determination of the content of iodine, epoxy, and hydroxyl value (Table 3) and using FT-IR spectroscopy (Figure 2). The titration analysis results made it possible to determine the selectivity and efficiency of the conducted processes and the designation of the probability of undesirable occurrence of the transesterification process. The highest conversion rate was achieved for products of reactions conducted without the use of a solvent (EOP-2 and EOP-3). Whereby, at the same time, for these epoxidized products, we obtained the smallest values of efficiency and selectivity among all tested products. Epoxidized palm oil (EOP-3) obtained in the reaction conducted for 12 hours without the use of toluene was characterized by the smallest content of epoxy groups $\left(E V_{\mathrm{EOP}-3}=0.125 \mathrm{~mol} / 100 \mathrm{~g}\right)$ and the highest content of $-\mathrm{OH}$ groups $\left(H V_{\mathrm{EOP}-3}=37.88 \mathrm{mg} \mathrm{KOH} / \mathrm{g}\right)$, which may indicate the occurrence of an undesired reaction - the opening of the epoxide rings in modified palm

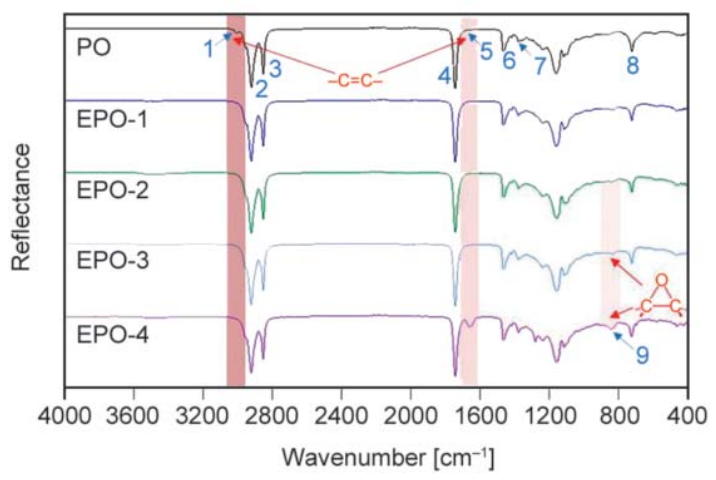

Figure 2. FT-IR ATR spectra of palm oil and its epoxidized derivatives.

Table 3. The properties of palm oil and products of epoxidation reactions.

\begin{tabular}{|l|c|c|c|c|c|c|c|c|}
\hline \multicolumn{1}{|c|}{ Oil } & $\begin{array}{c}\boldsymbol{I V} \\
{\left[\mathbf{g} \mathbf{I}_{\mathbf{2}} / \mathbf{1 0 0} \mathbf{~ g}\right]}\end{array}$ & $\begin{array}{c}\boldsymbol{E} \boldsymbol{V} \\
{[\mathbf{m o l} / \mathbf{1 0 0} \mathbf{g}]}\end{array}$ & $\begin{array}{c}\boldsymbol{H} \boldsymbol{V} \\
{[\mathbf{m g ~ K O H} / \mathbf{g}]}\end{array}$ & $\begin{array}{c}\boldsymbol{A} \boldsymbol{V} \\
{[\mathbf{m g ~ K O H} / \mathbf{g}]}\end{array}$ & $\begin{array}{c}\boldsymbol{X}^{\mathbf{a}, \mathbf{b}} \\
{[\mathbf{\%}]}\end{array}$ & $\begin{array}{c}\boldsymbol{E} \boldsymbol{O}_{\max }^{\mathbf{e x p}} \\
{[\mathbf{\%}]}\end{array}$ & $\begin{array}{c}\boldsymbol{R E} \boldsymbol{Y}^{\mathbf{a}, \mathbf{c}} \\
{[\mathbf{\%}]}\end{array}$ & $\boldsymbol{S E}^{\mathbf{a}, \mathbf{d}}$ \\
\hline PO & $52.6 \pm 0.9$ & $0.003 \pm 0.001$ & $35.1 \pm 0.6$ & $0.4 \pm 0.0$ & - & - & - & - \\
\hline EPO-1 & $10.4 \pm 0.2$ & $0.140 \pm 0.004$ & $63.8 \pm 0.1$ & $0.7 \pm 0.2$ & 80.1 & 1.92 & 59.7 & 0.74 \\
\hline EPO-2 & $1.1 \pm 0.4$ & $0.139 \pm 0.001$ & $80.4 \pm 1.3$ & $0.9 \pm 0.1$ & 98.0 & 1.07 & 33.3 & 0.34 \\
\hline EOP-3 & $0.8 \pm 0.1$ & $0.125 \pm 0.002$ & $37.9 \pm 0.4$ & $1.6 \pm 0.0$ & 98.5 & 1.05 & 32.8 & 0.33 \\
\hline EOP-4 & $7.7 \pm 0.0$ & $0.171 \pm 0.001$ & $26.6 \pm 1.2$ & $1.0 \pm 0.0$ & 85.4 & 1.62 & 50.4 & 0.59 \\
\hline
\end{tabular}

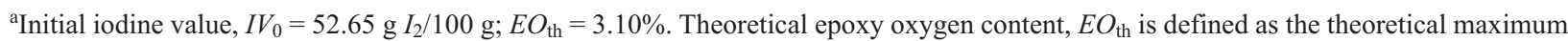
content of epoxy oxygen in $100 \mathrm{~g}$ of oil, calculated as $E O_{\mathrm{th}}=\left\{\left(I V_{0} / 2 A_{\mathrm{J}}\right) /\left[100+\left(I V_{0} / 2 A_{\mathrm{J}}\right) A_{\mathrm{O}}\right]\right\} A_{\mathrm{O}} \cdot 100$, where $A_{\mathrm{J}}=126.9 \mathrm{~g} / \mathrm{mol}$ and $A_{\mathrm{O}}=$ $16.0 \mathrm{~g} / \mathrm{mol}$

${ }^{\mathrm{b}}$ Double bond conversion, $X=\left[\left(I V_{0}-\mathrm{IV}\right) / I V_{0}\right] \cdot 100$.

${ }^{\mathrm{c}}$ Relative epoxy yield, $R E Y=\left(E O_{\max }^{\exp } / E O_{\text {th }}\right) \cdot 100$

${ }^{\mathrm{d}}$ Selectivity, $S E=E O_{\max }^{\exp } \cdot I V_{0} /\left[E O_{\mathrm{th}}\left(I V_{0}-I V\right)\right]$. 
oil. Epoxidized palm oil EOP-4, obtained in relatively mild temperature in the presence of solvent, was characterized by the highest $E V$ in comparison to other epoxidized products $\left(E V_{\mathrm{EOP}-4}=0.171 \mathrm{~mol} / 100 \mathrm{~g}\right)$. What is more, it is worth noting that the hydroxyl number of the product EOP-4 was the lowest of the others $\left(H V_{\mathrm{EOP}-4}=26.57 \mathrm{mg} \mathrm{KOH} / \mathrm{g}\right)$.

For all epoxidized products, the analysis FT-IR ATR was carried out (Figure 2). On the presented spectra, we marked a wavenumber range of $v=856-840 \mathrm{~cm}^{-1}$, which is characteristic for epoxy groups, as well as $v=1660-1640$ and $v=3030-2990 \mathrm{~cm}^{-1}$, assigned to unsaturated bonds $-\mathrm{C}=\mathrm{C}-$. Comparing the recorded spectrum of FT-IR for palm oil before epoxidation with the spectra of epoxidized palm oils, the disappearance of the band, which is characteristic for unsaturated bonds (at $3007 \mathrm{~cm}^{-1}$ ), is noticeable. At the same time new band at $v=842 \mathrm{~cm}^{-1}$, corresponding to epoxide groups, is observed.

\subsection{Synthesis of epoxy resin via epoxy fusion process of epoxidized palm oil and bisphenol A}

In the next stage of the research, we synthesized an epoxy resin using epoxidized palm oil EOP-4 $\left(E V_{\text {EOP-4 }}=0.117 \mathrm{~mol} / 100 \mathrm{~g}, I V_{\mathrm{EOP}-4}=17.1 \mathrm{~g} I_{2} / 100 \mathrm{~g}\right.$; $H V_{\mathrm{EOP}-4}=26.6 \mathrm{mg} \mathrm{KOH} / \mathrm{g}$ ), because, in comparison to other epoxidized products, it was characterized by the highest $E V$ and the lowest $H V$. Two polyaddition reactions were carried out. In the performed reactions, different amounts of BPA were used: (1) resulted from calculations using the formula (Equation (1)), describing the change in the amount of functional groups in the reactants (EOP_BPA(1)) [26] and (2) an equimolar ratio of hydroxyl groups of bisphenol and epoxy groups of modified palm oil (EOP_BPA(2)). The first method of carrying out the reaction was to obtain a product with the assumed content of epoxy groups because the weight ratio of the reactants was calculated on the basis of the content of epoxy groups (expressed by epoxy value) in epoxidized palm oil and the expected content of epoxy groups in the product. The equimolar ratio of functional groups of reagents, adopted in the second process, is typical for polyaddition/polycondensation reactions in which we want to obtain products of the highest molecular weight. Both epoxy fusion reactions were carried out in the presence of $\mathrm{LiCl}$ (in a ratio of 0.002 moles per 1 mole of BPA) as a catalyst. Applied catalyst, next to promoting the reaction between oxirane groups of modified vegetable oil and phenolic groups of bisphenol A, also prevents the gelation of the mixture. Both processes were carried out at $160^{\circ} \mathrm{C}$, in an inert gas atmosphere. The progress of the process was monitored every 15 minutes by the determination of the content of oxirane groups until the complete conversion of the epoxide groups (Figure 3). Based on the change of epoxy value (Figure 3), greater reaction progress of the polyaddition process was observed for the EOP_BPA(2) reaction using an equimolar ratio of hydroxyl groups of bisphenol and epoxy groups of modified palm oil. As a result, in this reaction, no oxirane groups were observed after 45 min of conducting the reaction. Two polyaddition products were obtained:

EOP_BPA(1) $(E V=0.000 \mathrm{~mol} / 100 \mathrm{~g}$,

$L O H=74.2 \mathrm{mg} \mathrm{KOH} / \mathrm{g})$ and

EOP_BPA(2) $(E V=0.000 \mathrm{~mol} / 100 \mathrm{~g}$,

$L O H=106.4 \mathrm{mg} \mathrm{KOH} / \mathrm{g}$ ) (Table 4).

Values of the acid number in both products were not significantly different from each other; however, a clear difference was observed in the case of the hydroxyl number (Table 4). Product EOP_BPA(2) (compared to EOP_BPA(1)), due to the use of larger amount of bisphenol $\mathrm{A}$ in the synthesis, contained more $-\mathrm{OH}$ groups. In turn, product EOP_BPA(1), obtained in the reaction, for which the amount of BPA was calculated based on the equation (paragraph no. 2.2), was characterized by the highest value of number and weight average molecular weight $\left(\bar{M}_{\mathrm{n}}=\right.$ $4858 \mathrm{~g} / \mathrm{mol}$ and $\bar{M}_{\mathrm{w}}=10878 \mathrm{~g} / \mathrm{mol}$ for EOP_BPA(1) and $\bar{M}_{\mathrm{n}}=3825 \mathrm{~g} / \mathrm{mol}$ and $\bar{M}_{\mathrm{w}}=8482 \mathrm{~g} / \mathrm{mol}$ for EOP_BPA(2), respectively) (Table 4). Based on the analytical determinations, there are no free epoxy groups found in obtained epoxy fusion products EOP_BPA(1) and EOP_BPA(2). Additionally, on the FT-IR spectra of polyaddition products (Figure 4), there are signals which are associated with the aromatic ring (at the range of wavenumber: $v=830$ and $\left.v=1610-1590 \mathrm{~cm}^{-1}\right)$. Moreover, for both epoxy fusion products, the appearance of a wide band at the range of wave number $v=3640-3140 \mathrm{~cm}^{-1}$, corresponding to - $\mathrm{OH}$ groups, was also pronounced. Conducting the polyaddition reaction using an amount of BPA, which was calculated based on the given equation (EOP_BPA(1)), results in a product characterized by a higher value of number and weight average molecular weight. Moreover, it is worth noting that caring out the polyaddition reactions using different amounts of BPA, mainly resulted in differences in 


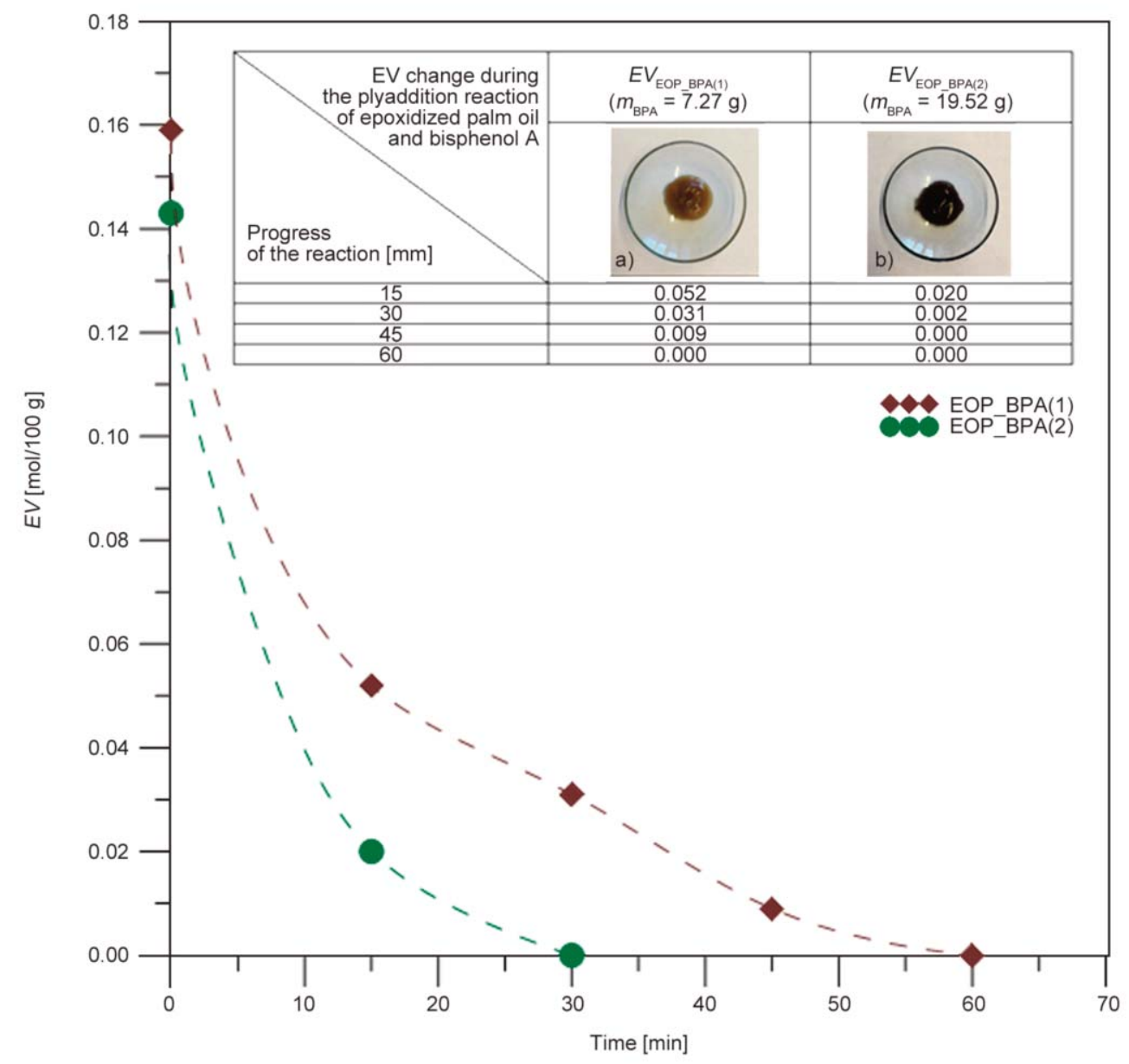

Figure 3. Changes in the content of epoxy groups in the reaction mixture during the process of polyaddition of epoxidated palm oil and bisphenol A. a) EOP_BPA(1), b) EOP_BPA(2)).

Table 4. Properties of polyaddition product based on epoxidized palm oil and bisphenol A.

\begin{tabular}{|l|c|c|c|c|c|c|}
\hline \multicolumn{1}{|c|}{ Properties } & $\begin{array}{c}\boldsymbol{E} \boldsymbol{V} \\
{[\mathbf{m o l} / \mathbf{1 0 0} \mathbf{g}]}\end{array}$ & $\begin{array}{c}\boldsymbol{H} \boldsymbol{V} \\
{[\mathbf{m g ~ K O H} / \mathbf{g}]}\end{array}$ & $\begin{array}{c}\boldsymbol{A} \boldsymbol{V} \\
{[\mathbf{m g ~ K O H} / \mathbf{g}]}\end{array}$ & $\begin{array}{c}\overline{\boldsymbol{M}}_{\mathbf{n}} \\
{[\mathbf{g} / \mathbf{m o l}]}\end{array}$ & $\begin{array}{c}\overline{\boldsymbol{M}}_{\mathbf{w}} \\
{[\mathbf{g} / \mathbf{m o l}]}\end{array}$ & $\boldsymbol{P I}$ \\
\hline EOP_BPA(1) & 0.000 & 74.2 & 0.56 & 4858 & 10878 & 1.49 \\
\hline EOP_BPA(2) & 0.000 & 106.4 & 0.52 & 3825 & 8482 & 1.47 \\
\hline
\end{tabular}

the progress of the reaction and final value of the hydroxyl number. It can be assumed that the observed

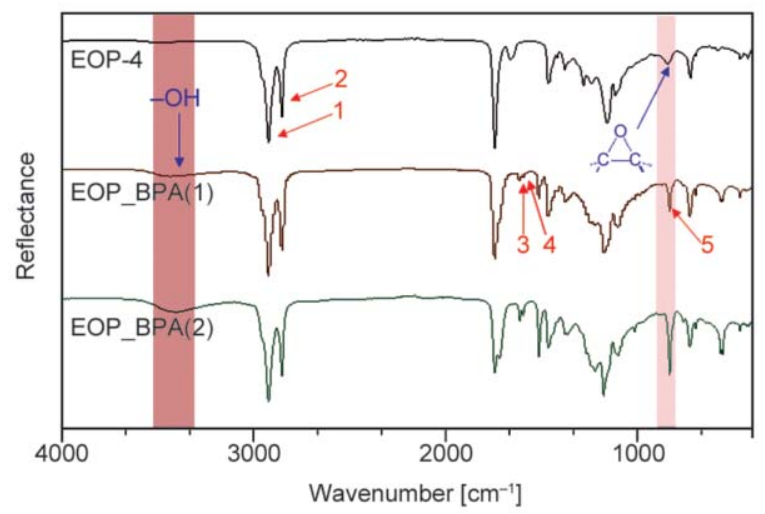

Figure 4. FT-IR spectra of epoxidized palm oil and its polyaddition products EOP_BPA(1) and EOP_BPA(2). phenomenon might be related to the mechanisms of the reaction, presented in Figure 5. First, the reaction between the oxirane ring of EOP with hydroxyl group of BPA occurs. Then, two variants are possible: (i) the reaction of the hydroxyl group of attached BPA with an epoxy ring of another molecule of modified vegetable oil or (ii) the reaction of another epoxy ring of the newly created dimer with a different molecule of BPA. In the second performed reaction, with a larger amount of used BPA, leading to a product EOP_BPA(2), the initial stage of the reaction could possibly result in the formation of larger amount of dimers, which, due to the larger amount of BPA in the environment, comparing to reaction EOP_BPA(1), easier attached another relatively small molecule of BPA than oil molecule. The confirmation of the 

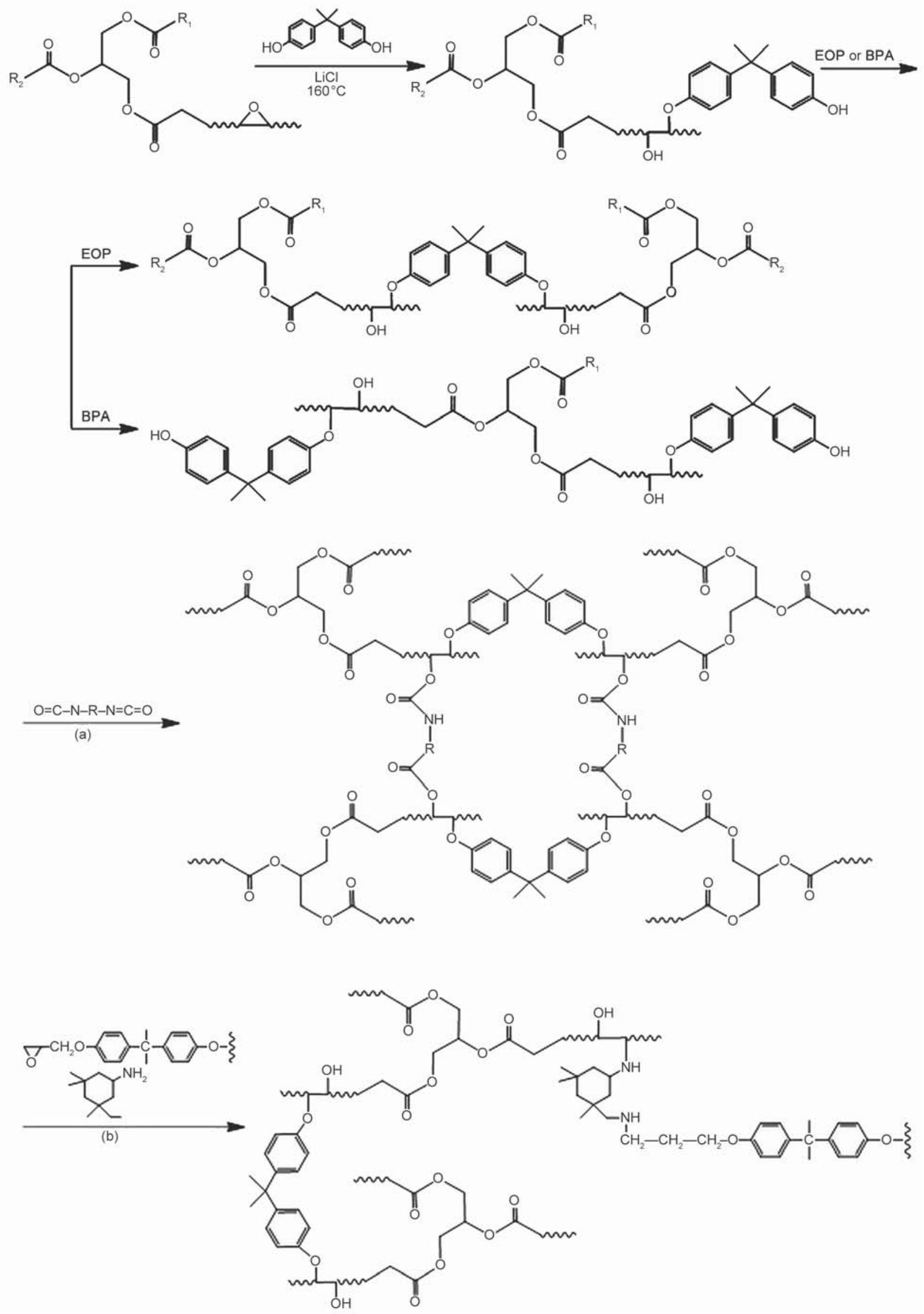

Figure 5. Scheme of obtaining epoxy compositions using palm oil derivatives as: (a) substrates of stand-alone epoxypolyurethane materials and (b) as modifiers of a commercial bisphenol A-based low molecular weight epoxy resin. 
presumed course of the reaction EOP_BPA(2) is a faster disappearance of oxirane groups, resulting in a faster decrease in the epoxide value over time. In the case of reaction EOP_BPA(2), determined $E V$ after $15 \mathrm{~min}$ of conducting the process was $0.020 \mathrm{~mol} / 100 \mathrm{~g}$ and after $30 \mathrm{~min}-0.002 \mathrm{~mol} / 100 \mathrm{~g}$, while for EOP_BPA(1) 0.052 and $0.031 \mathrm{~mol} / 100 \mathrm{~g}$, respectively. Additionally, it is also worth noting here that the reaction progress inseparable links to the increase in viscosity, leading to greater difficulties in the mobility of molecules. So that with a presumably larger amount of dimers, if most of them reacted, creating even larger molecules, the increase in viscosity was much greater than in the case of reaction using smaller amount of BPA (EOP BPA(1)). This way for product EOP_BPA(1) not only number, but also weight average molecular weight was slightly larger than EOP_BPA(2).

In order further confirmation of the structure of the obtained products ${ }^{1} \mathrm{H}$ NMR (Figure 6 and 8) and ${ }^{13} \mathrm{C}$ NMR (Figure 7 and 9), analysis of the palm oil derivatives was performed. Epoxidized palm oil and polyaddition products were dissolved in deuterated acetone $\left(\mathrm{CD}_{3} \mathrm{COCD}_{3}\right.$, acetone- $\left.d_{6}\right)$, and both ${ }^{1} \mathrm{H} \mathrm{NMR}$ and ${ }^{13} \mathrm{C}$ NMR spectra were recorded. On the recorded ${ }^{1} \mathrm{H}$ NMR spectrum of EOP_BPA products (Figure 8) the presence of signals related to the introduction of bisphenol A into the reaction system was found. These signals are visible respectively at 7.02-7.00 and
6.69-6.68 ppm (denoted as $\mathbf{0}$ and $\mathbf{n}$, protons of the aromatic ring), $3.58 \mathrm{ppm}$ ( $\mathbf{m}$, protons of the phenyl group), and $1.58 \mathrm{ppm}$ (p, protons of the methyl group) [25]. The intensity of signals related to protons of the phenyl group in combination with the spectrum of bisphenol A is several times lower, which could indicate that in the case of both polyadditions EOP_BPA(1) and EOP_BPA(2) immediately after the reaction between oxirane ring of EOP with the hydroxyl group of BPA, proceeded the reaction of the hydroxyl group of attached BPA with an epoxy ring of another molecule of epoxidized palm oil. The only difference between spectra recorded for the polyaddition products is the larger intensity of signal $\mathrm{p}$, related to protons of methyl groups of BPA, within the spectrum EOP_BPA(2). This observation is related to the larger amount of bisphenol A used for the reaction resulted from an equimolar ratio of hydroxyl groups of bisphenol and epoxy groups in modified palm oil. Additionally, on the ${ }^{1} \mathrm{H}$ NMR spectra recorded for samples of the EOP_BPA polyaddition products, alike at the ${ }^{1} \mathrm{H}$ NMR spectrum of epoxidized palm oil (Figure 6), relatively broad signals in the range of $\delta=1.30-2.15 \mathrm{ppm}$ were found. The shape of these signals most likely might be explained by the phenomenon of overlapping several signals with similar chemical shift values, which corresponds to the presence of various fatty acid residues in epoxidized palm oil. Differences in values of individual

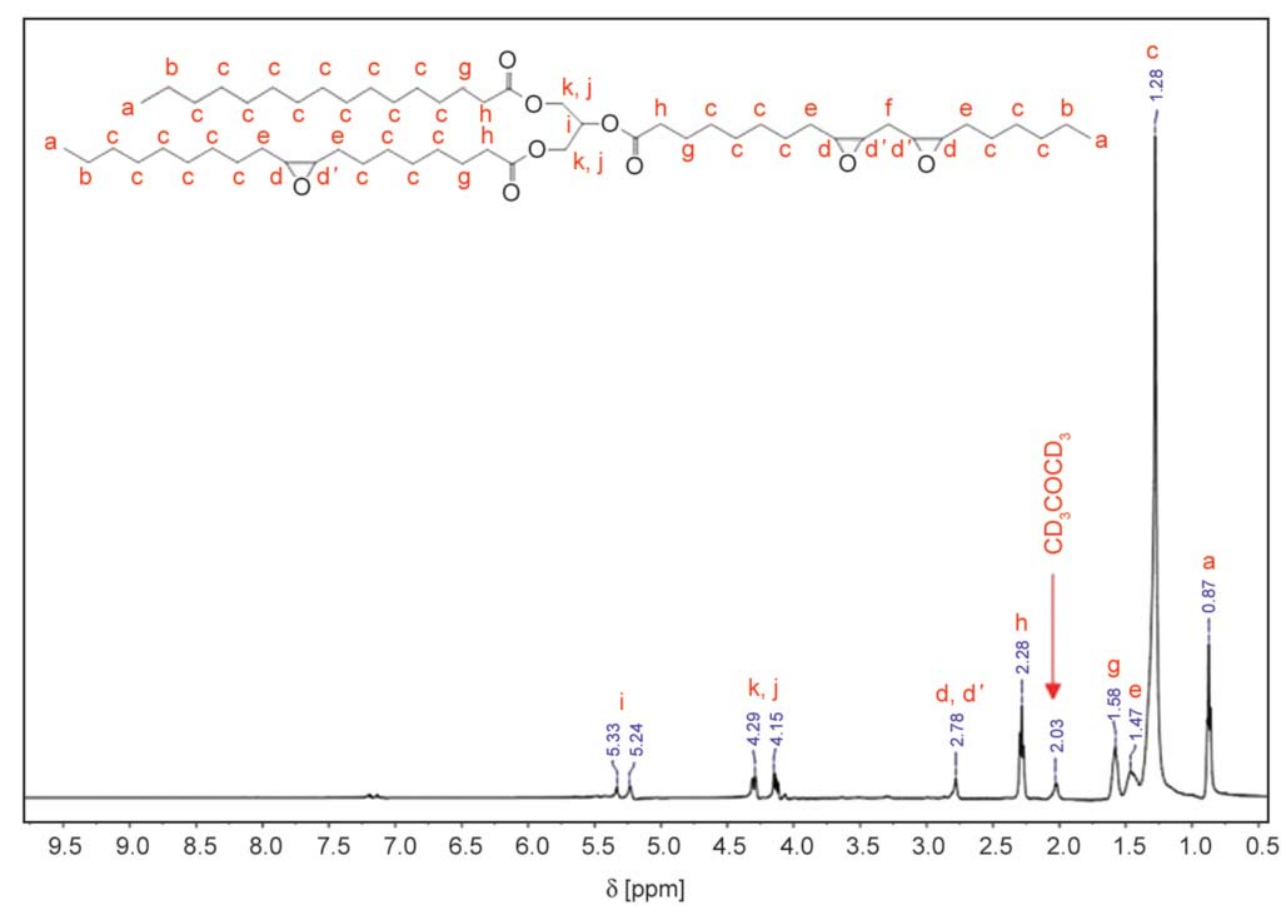

Figure 6. ${ }^{1} \mathrm{H}$ NMR spectrum of epoxidized palm oil. 


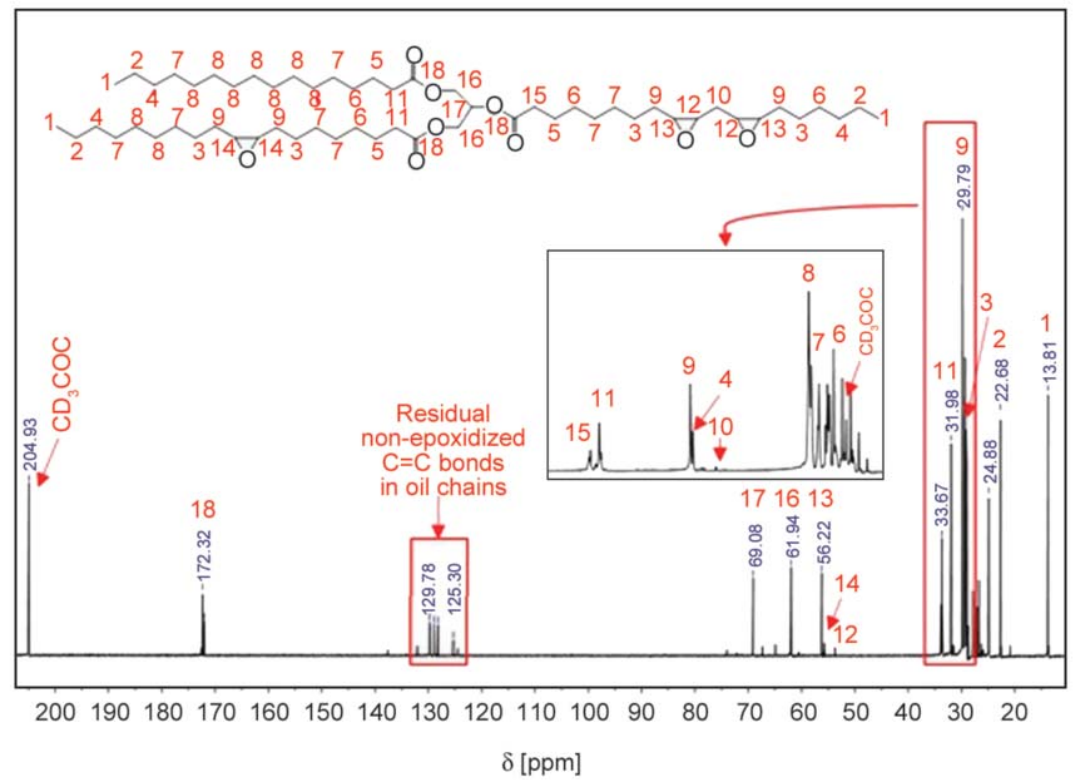

Figure 7. ${ }^{13} \mathrm{C}$ NMR spectrum of epoxidized palm oil.

chemical shifts in the case of overlapping signals are small and result from subtle differences in the chemical environment of the relevant protons. Moreover, on the ${ }^{1} \mathrm{H}$ NMR spectra of both EOP and EOP_BPA products, the triplet peak signal at $\delta=0.89$ $0,86 \mathrm{ppm}$ indicates the terminal methyl protons (denoted as a, $-\mathrm{CH}_{3}$ ) and the signals from backbone methylene protons in the saturated chains of the fatty acid $\left(\mathbf{c},-\mathrm{CH}_{2}-\mathrm{CH}_{2}-\mathrm{CH}_{2}-\right)$ are present at $\delta=$ $1.28 \mathrm{ppm}$. On the spectrum of EOP signals in the $\delta=$ $2.78 \mathrm{ppm}$ (denoted as $\mathbf{d}, \mathbf{d}^{\prime}$ ) might be assigned to the methine protons of the epoxy ring. The presence of these signals is not visible on the spectra of polyaddition products. The lack of these signals in the company of recorded increase in intensity of signals characteristic for the secondary hydroxyl group indicates the occurrence of the reaction between oxirane rings of modified vegetable oil and hydroxyl groups of bisphenol A during the epoxy fusion process. Additionally, the signal observed in the $\delta=$ 1.40-1.47 ppm region on EOP spectrum could be attributed to the methylene groups in the $\alpha$-position of the epoxy ring (protons denoted as e, OXIRANE RING-CH ${ }_{2}-$ OXIRANE RING). Following peaks, visible at NMR spectra of epoxidized palm oil derivatives, are at $\delta=1.58 \mathrm{ppm}$ and can be assigned to protons in position $\beta$ to the $>\mathrm{C}=\mathrm{O}$ of the glycerol backbone $-\mathrm{C}=\mathrm{OCH}_{2}-\mathrm{CH}_{2}$ (protons denoted as $\mathbf{g}$ ), while the signal at $\delta=2.27-2.30 \mathrm{ppm}$ refers to methylene protons in the $\alpha$ position to the carbonyl group $\mathrm{C}=\mathrm{OCH}_{2}-\mathrm{CH}_{2}$ (respectively $\mathbf{h}$ on the spectrum). Next characteristic signals for triglyceride molecule are visible respectively at $\delta=5.33-5.24 \mathrm{ppm}$ [triplet, $\mathbf{i}$, methine glyceryl protons $\left.-\mathrm{CH}_{2}(\mathrm{O}) \mathrm{CH}(\mathrm{O}) \mathrm{CH}_{2}(\mathrm{O})-\right]$, 4.29-4.15 ppm [ $\mathbf{k}, \mathbf{j}$, glyceryl methylene protons $\left.-\mathrm{CH}_{2}(\mathrm{O}) \mathrm{CH}(\mathrm{O}) \mathrm{CH}_{2}(\mathrm{O})-\right]$.

On the ${ }^{13} \mathrm{C}$ NMR of epoxidized palm oil, deuterated acetone, which was used as the solvent, show two signals: at $\delta=29.0$ and $\delta=204.9 \mathrm{ppm}$. The first signal is assigned to its methyl groups and the second - to the carbonyl group. The NMR peaks related to epoxidized palm oil are attributed by following chemical shifts: 172.03-172.32 ppm (C18, carbonyl carbon atoms of triacylglycerol bonds $>\mathrm{C}=\mathrm{O}$ ), $69.08 \mathrm{ppm}[\mathbf{C 1 7}$, assign to carbon atoms of glyceryl methine group $\left.-\mathrm{CH}_{2}(\mathrm{O}) \mathrm{CH}(\mathrm{O}) \mathrm{CH}_{2}(\mathrm{O})-\right], 61.94 \mathrm{ppm}$ [C16, methylene carbon atoms of glyceryl $\left.-\mathrm{CH}_{2}(\mathrm{O}) \mathrm{CH}(\mathrm{O}) \mathrm{CH}_{2}(\mathrm{O})\right]$, 53.81-56.22 ppm (C12, $\mathrm{C13}$ and $\mathrm{C14}$, the carbon atoms of oxirane rings), $31.62 \mathrm{ppm}(\mathbf{C 1 0}$, the carbon atoms of the methylene group between the two epoxy moieties in linoleic chain), $31.90 \mathrm{ppm}$ (C9, the carbon atoms of the methylene groups at the $\alpha$ position with respect to the epoxy groups), 29.60, 24.96 and 29.74 (the carbon of methylene groups of fatty acid backbone: $\mathbf{C 6}$ - in the position $\gamma$ to the carbonyl groups of the glycerol $>\mathrm{C}=\mathrm{OCH}_{2} \mathrm{CH}_{2} \mathrm{CH}_{2-}, \mathbf{C 5}-$ the $\beta$ carbon glycerol $>\mathrm{C}=\mathrm{OCH}_{2} \mathbf{C H}_{2} \mathrm{CH}_{2}-$ and $\mathbf{C 8}$ - other methylene groups). The carbon atom of terminus methyl groups of the fatty acid backbone (denoted as $\mathbf{C 1}$ in Figure 7, $-\mathrm{CH}_{2}-\mathrm{CH}_{3}$ ) gives a signal at $13.8 \mathrm{ppm}$. Signals assigned to methylene groups in the $\alpha$ position with respect to the methyl terminal groups appear at $\delta=$ 22.68 ppm, $\left(\mathbf{C 2},-\mathbf{C H}_{2} \mathrm{CH}_{3}\right)$, while the $\beta$ methylene 

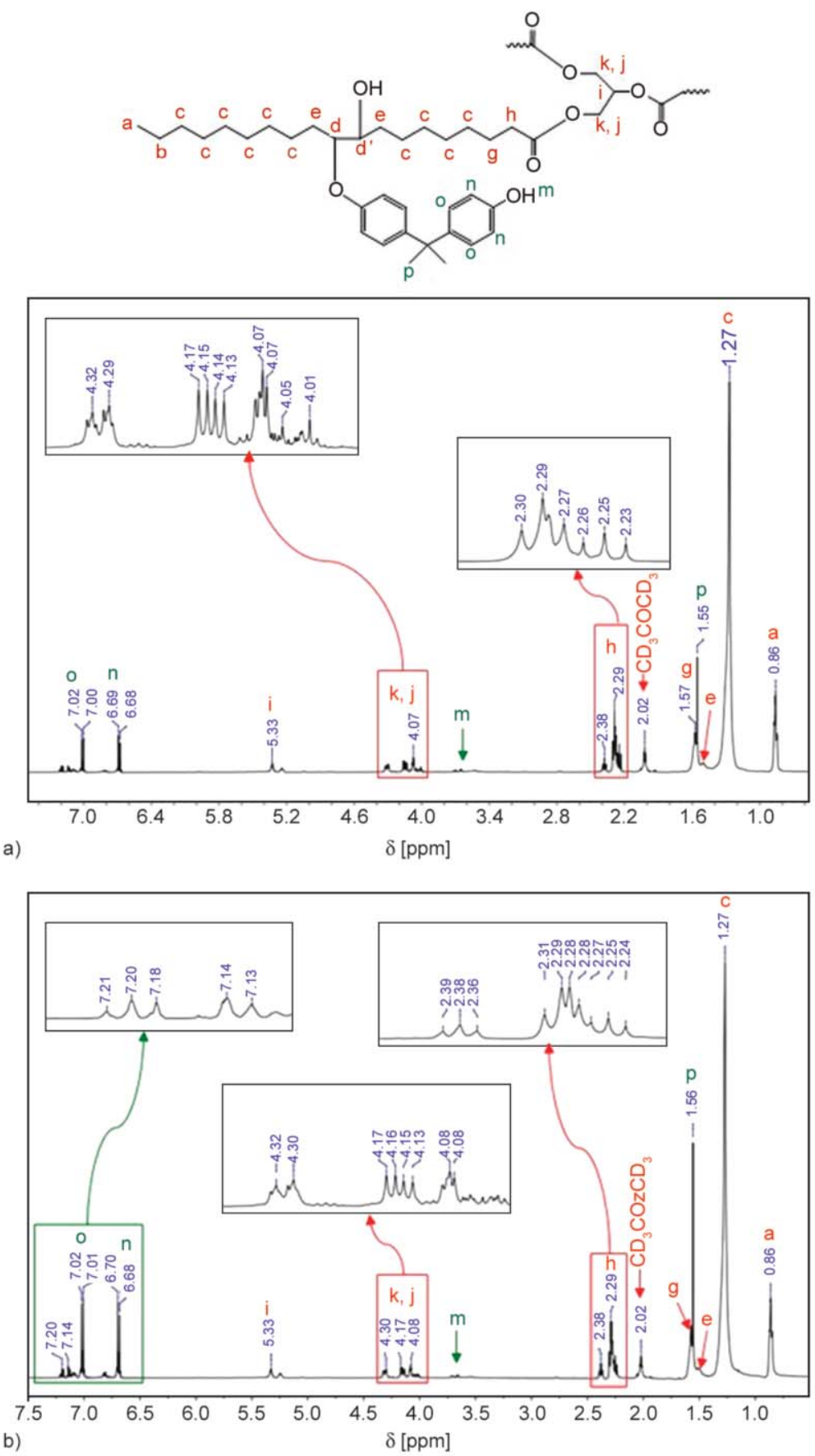

Figure 8. ${ }^{1} \mathrm{H}$ NMR spectrum of polyaddition products of palm oil derivatives and bisphenol A: a) EOP_BPA(1) and b) EOP_BPA(2).

carbons to the methyl, $\mathbf{C 4}$, at $29.60 \mathrm{ppm}$. In addition, C7 - the methylene in $\gamma$ position with respect to the methyl terminal groups give a signal at $29.74 \mathrm{ppm}$. It is also worth noting that, on the presented in Figure $7{ }^{13} \mathrm{C}$ NMR spectrum of epoxidized palm oil, there are also visible signals related to the presence of unsaturated carbon of the palm oil fatty acids (the group of signals about $\delta=125.30 \mathrm{ppm}$ and $\delta=$ $129.78 \mathrm{ppm})$. As mentioned earlier, the presence of such groups was also determined using titration and spectroscopic methods.
Alike ${ }^{1} \mathrm{H}$ NMR spectrum, on ${ }^{13} \mathrm{C}$ NMR spectrum of polyaddition products (Figure 9) are visible signals related both to epoxidized palm oil and introduced during the epoxy fusion process - bisphenol A. The signals characteristic for BPA might be listed as follows: $\delta=155.0 \mathrm{ppm}, \delta=141.94 \mathrm{ppm}$, around $\delta=$ $129.0 \mathrm{ppm}$ and $\delta=114.61 \mathrm{ppm}$ (carbon atoms of aromatic rings; C19, C20, C21 and C22, respectively), $\delta=41.24 \mathrm{ppm}(\mathbf{C 2 4}$, carbon atom between two aromatic rings of BPA), and $\delta=30.76 \mathrm{ppm}(\mathbf{C 2 3}$, carbon atoms of methyl groups of bisphenol A). Additionally, 

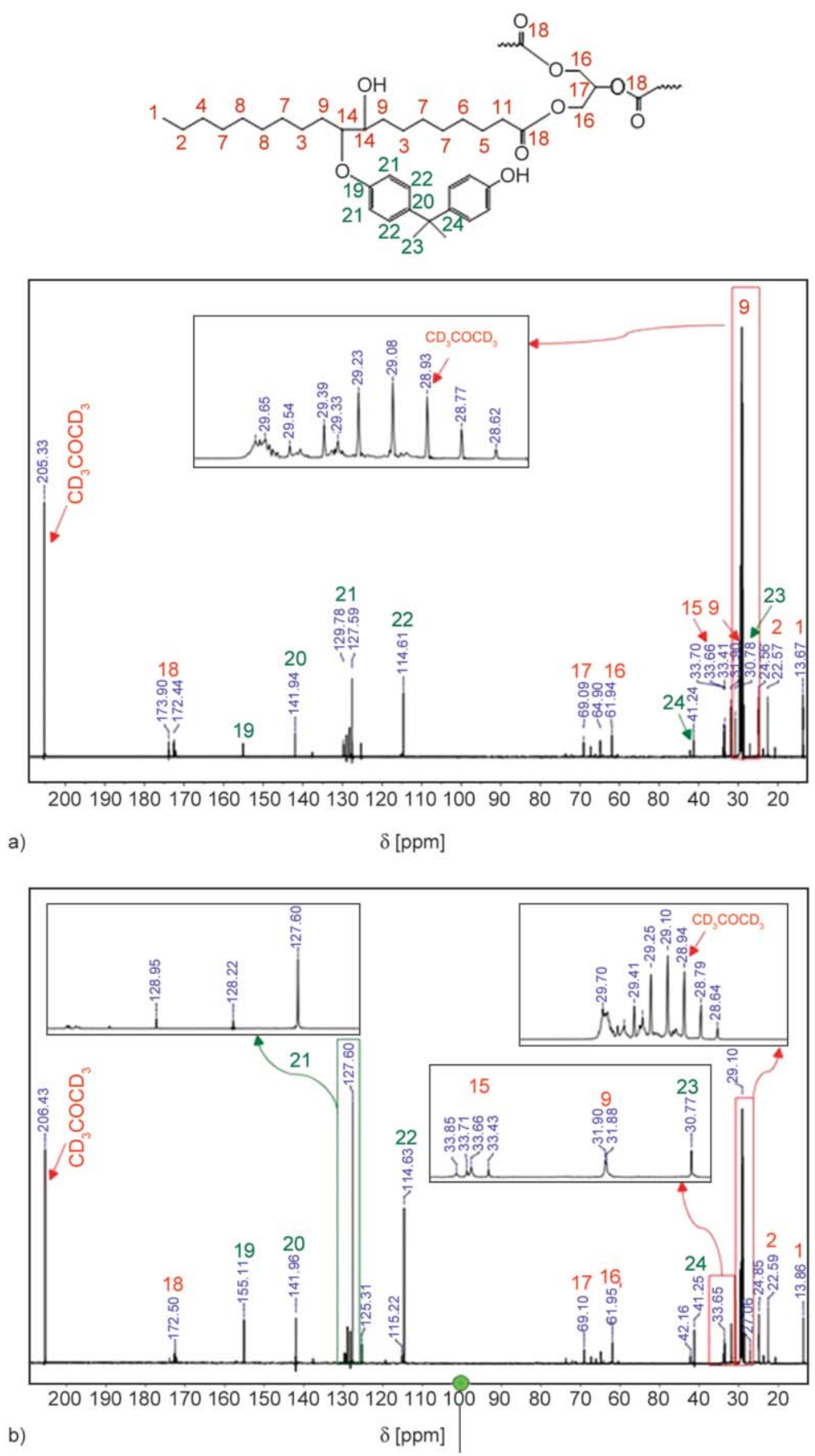

Figure 9. ${ }^{13} \mathrm{C}$ NMR spectrum of polyaddition products of palm oil derivatives and bisphenol A: a) EOP_BPA(1) and b) EOP_BPA(2).

while comparing spectra of both polyaddition products of epoxidized palm oil with BPA, it is worth noting that no presence of carbon atoms of oxirane rings (denoted as C12-C14 on EOP spectrum) is stated, as evidence of the occurrence of the reaction between epoxy rings of EOP and hydroxyl group of BPA. Additionally, in the area of $\delta=129.78 \mathrm{ppm}$ and $\delta=$ $125.30 \mathrm{ppm}$ (residual of non-epoxidized $\mathrm{C}=\mathrm{C}$ bonds in oil chains was observed on the spectrum of epoxidized palm oil) overlapping with signals of $\mathbf{C 2 0}$, C21 carbon atoms of aromatic rings of BPA. While comparing spectra EOP_BPA(1) and EOP_BPA(2), the increase of the intensity of signals related to $\mathbf{C 1 9}$, C20 and C21 is observed, which might indicate the increase of the number of carbon atoms of BPA occurring in the close neighborhood of triglyceride alkyl chains.

\subsection{Cured epoxy products obtained with the use of palm oil derivatives}

In the next step of performed studies, we prepared numerous compositions using obtained polyaddition 
products. We tested two different approaches (Figure 5): (1) application of the polyaddition products as independent epoxy materials, which may be crosslinked in the reaction with diisocyanates, and (2) as modifiers of a commercial bisphenol A-based low molecular weight epoxy resin crosslinked next with diamines.

The polyaddition products: EOP_BPA(1) and EOP_BPA(2) obtained in the first stage of the research, were crosslinked using isocyanates, typically applied in the polyurethane technology. Hydroxyl groups, which are present in the structure of polyaddition products, are involved in crosslinking using isocyanates, and therefore even the unbound BPA will also be incorporated into the structure of the obtained PE-PU material.

By the crosslinking of EOP_BPA products with isocyanates of different chemical structures, it had been observed that obtained materials have various mechanical characteristics. Unfortunately, most of the crosslinking tests that were carried out using isocyanates based on HDI and TDI did not bring the intended results (Figure 10). When HDI-based isocyanate was used, the curing process wasn't complete or it took too long, while for TDI-based isocyanate, the obtained materials were very fragile. In addition, for some compositions, numerous air bubbles were found inside the crosslinked materials. Nevertheless, crosslinking of EOP_BPA using 4,4'methylenebis(phenyl isocyanate) resulted in obtaining the epoxy-polyurethane compositions with satisfactory macroscopic properties (such as smooth surface, no visible air bubbles, non-crumbling during removal from the mold). The obtained results of performed tests might be related to the chemical structure of chosen isocyanate, used as a curing agent [30, 31]. In the case of HDI, an aliphatic isocyanate, obtained material did not crosslink, or the curing process took too long, resulting in very fragile material characterized by very small mechanical resistance. On the other hand application of MDI and TDI

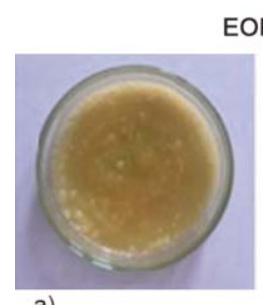

EOP_BPA(1)

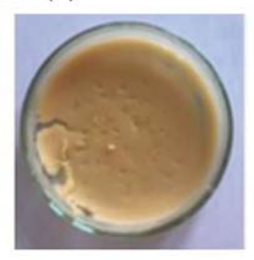

resulted in obtaining cured samples of diverse mechanical resistance. Fragility and the presence of air bubbles in the case of compositions prepared with the use of TDI may arise from its relatively greater reactivity compared to MDI, resulting in promptly increasing viscosity and excessively rapid crosslinking. This way, the release of air bubbles introduced during mixing and reaction of all available functional groups with the hardener was difficult or impossible. For aromatic diisocyanates, the difference in MDI and TDI structure leads to polymer materials with different mechanical performances, crosslinked with their use. MDI is a linear and symmetric molecule with two aromatic rings. Such chemical structure results in relatively close co-existence of urethane and ester groups, and potential chance of intermolecular plasticization and relatively longer curing time, and worse mechanical properties in comparison to material cured with TDI.

Samples for further tests were prepared in accordance with the applicable standards - the calculated amount of hardener, deaerator, and catalyst (Dabco T9) was added to the weighed amount of the polyaddition product. The entire composition was mixed thoroughly, deaerated, and poured into previously prepared molds. Samples were crosslinked at room temperature for $72 \mathrm{~h}$, and then the process was continued for another $24 \mathrm{~h}$ at $80^{\circ} \mathrm{C}$. Here it is worth noting that curing of composition without the use of catalyst failed; after 10 days, samples were barely crosslinked with clearly visible numerous air bubbles in the entire volume of the sample. That is why further discussion is focused on compositions prepared with the use of the catalyst. A number of tests were carried out for the obtained epoxy-polyurethane materials, including the determination of the mechanical and morphological analysis. Upon the obtained results, it was found that samples based on a polyaddition product with a higher hydroxyl number (EOP_BPA(2)/ MDI, $L O H=106.4 \mathrm{mg} \mathrm{KOH} / \mathrm{g}$ ) exhibit greater mechanical strength compared to material synthesized

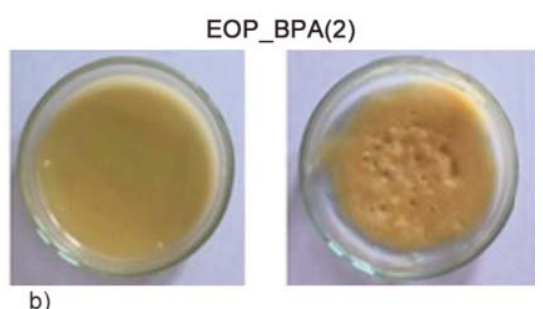

b)

Figure 10. Crosslinking attempts using HDI and TDI as hardeners. a) EOP_BPA(1), b) EOP_BPA(2). 
with the polyaddition product characterized by $\mathrm{LOH}=$ $74.2 \mathrm{mg} \mathrm{KOH} / \mathrm{g}$ (EOP_BPA(1)/MDI) (Table 5). The tensile strength of the composition EOP_BPA(2)/ MDI (2.6 MPa) is almost three times, and its elongation at break $(36.2 \%)$ - five times greater than composition EOP_BPA(1)/MDI (0.9 MPa and 7.0\%, respectively). Obtained results directly might be correlated with the chemical structure of the polyaddition products - higher content of hydroxyl groups impact the crosslinking density of the compositions and thus their hardness (54.2 and $78.3^{\circ} \mathrm{Sh} \mathrm{A}$, respectively for EOP_BPA(1) and EOP_BPA(2)). On the other hand, recorded results show that compositions based on palm oil derivatives crosslinked with MDI exhibit worse mechanical properties than those obtained for such materials using polyadditon products of soybean oil [32]. According to the conducted research, samples ESBO_BPA/MDI (ESBO_BPA: $E V=0.118 \mathrm{~mol} / 100 \mathrm{~g}$ and $H V=144 \mathrm{mg} \mathrm{KOH} / \mathrm{g}$ ) were characterized by the tensile strength of $8.0 \mathrm{MPa}$, elongation at break $-7.2 \%$, and tensile modulus of 290.2 MPa. Values of modulus of elasticity obtained for composition based on palm oil derivatives were respectively: $19.0 \mathrm{MPa}$ for EOP_BPA(1) and 10.7 MPa for EOP_BPA(2). Moreover, it is worth noting that in contrast to crosslinked samples of EOP_BPA/MDI, material ESBO_BPA/MDI still contains oxirane groups, which might be used in the process of obtaining double-layer materials [33]. Additionally, since the application of modified vegetable oils is also used in other than epoxy resins polymeric materials including polyurethanes, obtained results for materials crosslinked with isocyanates might be compared to those for samples based on novel polyol produced from palm oil-based methyl ester. The biodiesel based polyol was blended in equimolar ratios with natural oil polyols produced from palm olein, which were reacted with an aromatic diisocyanate to produce elastomers [34]. Bio-based PU was synthesized using palm olein-based polyols, prepared by the epoxidation of palm olein and their subsequent reaction with short-chain hydroxyl-functional reactants. Two polyols were used: Pioneer M-60 - characterized by a high content of secondary hydroxyl groups and a functionality of 2.8 and Pioneer E-135 - polyol containing both primary and secondary hydroxyl groups and a functionality of 5.2. The tensile strength and hardness of crosslinked materials were higher for elastomers based on Poly-FAME-EG/Pioneer E-135 polyol with higher functionality (0.53 MPa, $21^{\circ} \mathrm{Sh}$ for Pioneer M-60 and 2.78 MPa, $67^{\circ} \mathrm{Sh}$ for Pioneer E-135, respectively). At the same time, the obtained value of its tensile strength was higher by $0.2 \mathrm{MPa}$ comparing to the value obtained for EOP_BPA(2)/MDI, while for material based on Pioneer M-60 - lower by $0.4 \mathrm{MPa}$ as against to EOP_BPA(1)/MDI (0.9 MPa for EOP_BPA(2)/MDI and 2.6 MPa for EOP_BPA(1)/MDI, respectively). Additionally, for PU samples, lower values of Shore A hardness were obtained comparing to those of EOP_BPA/MDI materials $\left(54.2^{\circ} \mathrm{Sh}-\right.$ EOP_BPA(1)/ MDI and $78.3^{\circ} \mathrm{Sh}$ for EOP BPA(2)/MDI). On the other hand, Poly-FAME-EG/Pioneer E-135 crosslinked samples exhibit higher values of elongation at the break $-133 \%$ comparing to $7.0 \%$ for EOP_BPA(1)/MDI and $36.2 \%$ for EOP_BPA(2)/MDI.

In turn, in the second approach, we used polyaddition products as modifiers of a commercial bisphenol A-based low molecular weight epoxy resin. Both EOP_BPA(1) and EOP_BPA(2) are solid materials. Nevertheless, they are very well miscible with the resin under laboratory conditions. Therefore, the obtained polyaddition products were used as 5,10 , and

Table 5. Mechanical properties of cured compositions based on epoxidized palm oil and bisphenol A.

\begin{tabular}{|ll|c|c|}
\hline \multicolumn{1}{|c|}{ Properties } & EOP_BPA(1)/MDI & EOP_BPA(2)/MDI \\
\hline Tensile strength & {$[\mathrm{MPa}]$} & $0.9 \pm 0.01$ & $2.6 \pm 0.01$ \\
\hline Modulus of elasticity & {$[\mathrm{MPa}]$} & $19.0 \pm 0.01$ & $10.7 \pm 0.60$ \\
\hline Elongation at break & {$[\%]$} & $7.0 \pm 2.8$ & $36.2 \pm 3.4$ \\
\hline Flexural strength & {$[\mathrm{MPa}]$} & $\mathrm{N} / \mathrm{A}$ & $1.9 \pm 0.2$ \\
\hline Elasticity flexural modulus & {$[\mathrm{MPa}]$} & $\mathrm{N} / \mathrm{A}$ & $84.0 \pm 2.0$ \\
\hline Deflection & {$[\%]$} & $\mathrm{N} / \mathrm{A}$ & $5.54 \pm 0.42$ \\
\hline Compressive strength & {$[\mathrm{MPa}]$} & $0.33 \pm 0.00$ & $2.83 \pm 0.01$ \\
\hline Compression set & {$[\%]$} & $2.2 \pm 0.18$ & $2.5 \pm 0.10$ \\
\hline Shore A Hardness & {$\left[{ }^{\circ} \mathrm{Sh}\right]$} & $54.2 \pm 1.7$ & $78.3 \pm 0.8$ \\
\hline Resilience & {$[\%]$} & $8.9 \pm 0.6$ & $10.0 \pm 0.9$ \\
\hline
\end{tabular}


$15 \mathrm{wt} \%$ additives for the epoxy compositions based on EPR 162. After obtaining a homogenous mixture of epoxy resin and the desired amount of EOP_BPA product, the compositions were mixed with isophorone diamine, chosen as a curing agent, in a stoichiometric ratio relative to the epoxy group content in each formulation. Additionally, each composition contained a small amount of the silicone polymer additive BYK-A 530 facilitated the air-releasing and defoaming of the compositions.

Polyaddition products do not contain free epoxy groups, therefore during crosslinking of prepared composition at room temperature, they are physical additives remaining in the cured composition in an unbound form. In this way, the modifier reduces the degree of the resin crosslinking, which is clearly visible in the strength properties of the tested compositions (Table 6). With increasing content of physical additive decreases the tensile strength of obtained material. At the same time, comparing two different polyaddition products, slightly lower values of tensile strength were obtained for the addition of EOP BPA(1)/BPA. However, an improvement in flexural strength was obtained for compositions containing $10 \mathrm{wt} \%$ of modifiers $(73.2 \mathrm{MPa}$ for EOP_BPA(1) and 77.6 MPa for EOP_BPA(2)). An interesting phenomenon is also observed while analyzing recorded values of modulus for those samples - in case of the addition of $10 \%$ of polyaddition product, one can observe relatively higher values while comparing to both unmodified sample of epoxy resin and samples with 5 and $15 \%$ of modifier (modulus of elasticity -1118.6 and $897.7 \mathrm{MPa}$ for EPR $162+10 \%$ EOP BPA(1) and

EPR162+10\%EOP_BPA(2), respectively and 924.7 MPa for pure EPR162; elasticity flexural modulus -3158.7 and $3435.2 \mathrm{MPa}$ for EPR162+10\%EOP_BPA(1) and EPR162+10\%EOP_BPA(2), respectively and 1996.0 MPa for pure EPR). An increase of modulus value indicates that the addition of $10 \%$ of polyaddition product significantly influences the elasticity of the material. At the same time, these materials are characterized by comparable values of impact strength without notched by the Charpy method and lower values of elongation at break and deflection. Obtained results might be compared to already published studies [23, 35]. Results from the tensile test, presented both within the mentioned studies as well as our investigation, show that all samples contain-

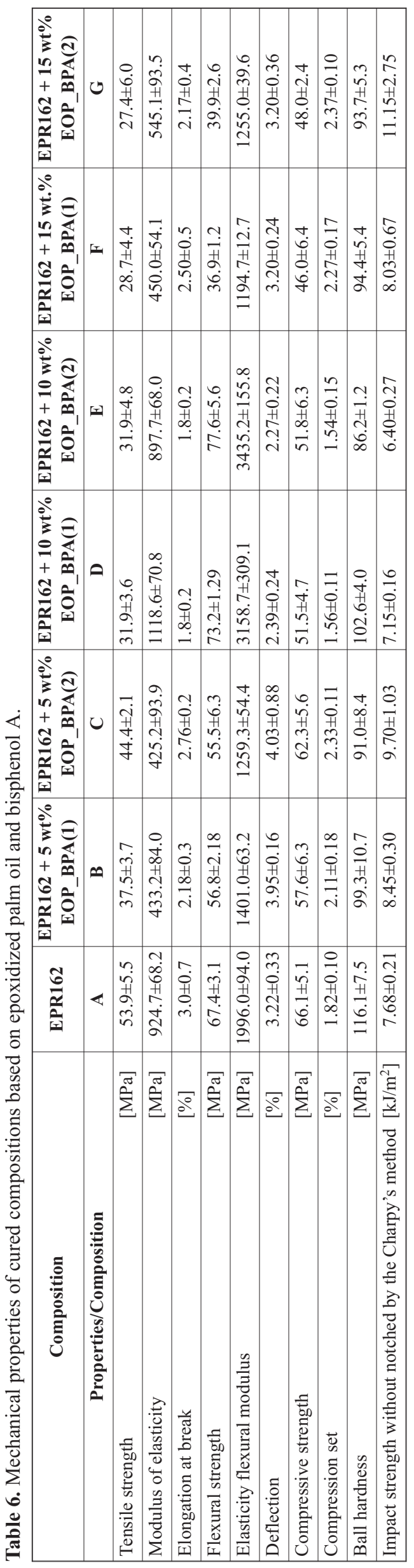


ing $10 \mathrm{wt} \%$ of modifier have reduced mechanical properties as compared to the unmodified epoxy resin. Moreover, the tested compositions exhibit worse properties than the polymer systems with the addition of EOP initially pre-polymerized in a reaction with isophorone diamine, which is built into the structure of the crosslinked composition [23]. Simultaneously samples containing polyaddition products (EPR162+10\%EOP_BPA(1) and

EPR162+10\%EOP_BPA(1)) exhibit, on the one hand, worse properties than material obtained with direct addition of $10 \mathrm{wt} \%$ EOP and cured with m-xylylenediamine, however, on the other hand comparable to those of the epoxy product prepared with the application of pre-mixed for $3 \mathrm{~h}$ EPO and curing agent [35].

The morphology analysis of the obtained samples, conducted by the SEM method (Figure 11), reveals that the unmodified epoxy resin sample revealed several brittle fractures without any phase separation (Figure 11a). In contrast, both tested materials based on EOP_BPA are characterized by a rough surface and numerous microdomains of polyaddition products specifically dispersed in an epoxy resin matrix (Figure 11b, 11c). Comparing SEM microphotographs of EPR162+10 wt\% EOP_BPA reveals that composition containing EOP_BPA(1) (Figure 11b) displayed a smaller amount of larger spherical domains, which are dispersed within the resin matrix. A two-phase system of compositions with a supplement of EOP_BPA polyaddition products is probably responsible for improving the impact strength of the resin, significant in the case of compositions with an addition of $15 \mathrm{wt} \%$ EOP_BPA(2) $\left(11.15 \mathrm{~kJ} / \mathrm{m}^{2}\right)$, because microdomains are capable of dissipating energy delivered in an impact way.

\section{Conclusions}

The aim of the study was the research on the synthesis of polymeric materials through the epoxy fusion process using modified palm oil derivatives. In the first stage, raw palm oil was subjected to epoxidation. In order to determine the best reaction conditions, the process was conducted under four variants. Based on the performed analysis, it was found that product EOP-4, obtained during $6 \mathrm{~h}$ process in relatively mild temperature conditions $\left(55^{\circ} \mathrm{C}\right)$ and toluene as a solvent, was characterized by the highest $E V$ in comparison to other epoxidized products $\left(E V_{\mathrm{EOP}-4}=\right.$ $0.171 \mathrm{~mol} / 100 \mathrm{~g}$ ). Additionally, it is worth noting that

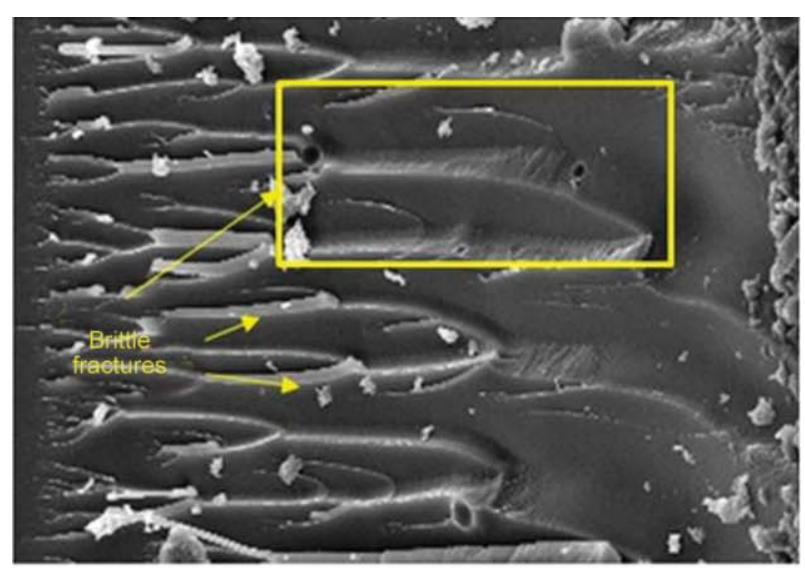

a)

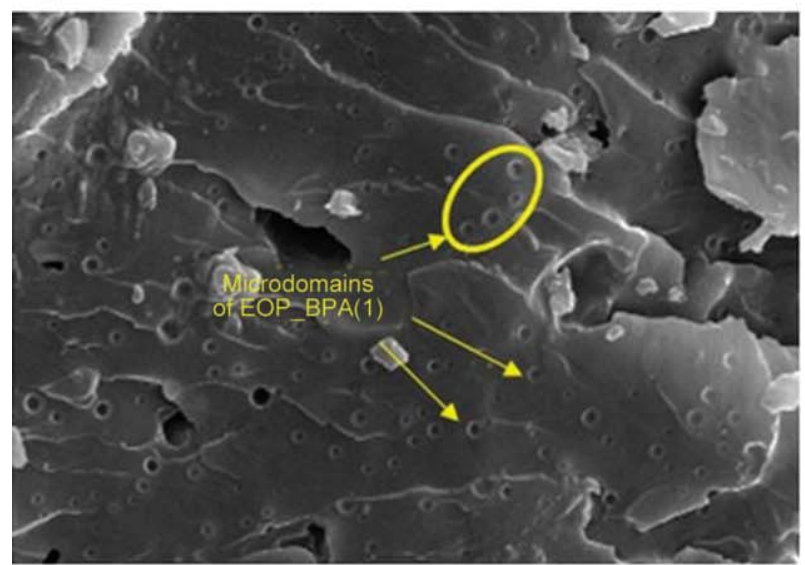

b)

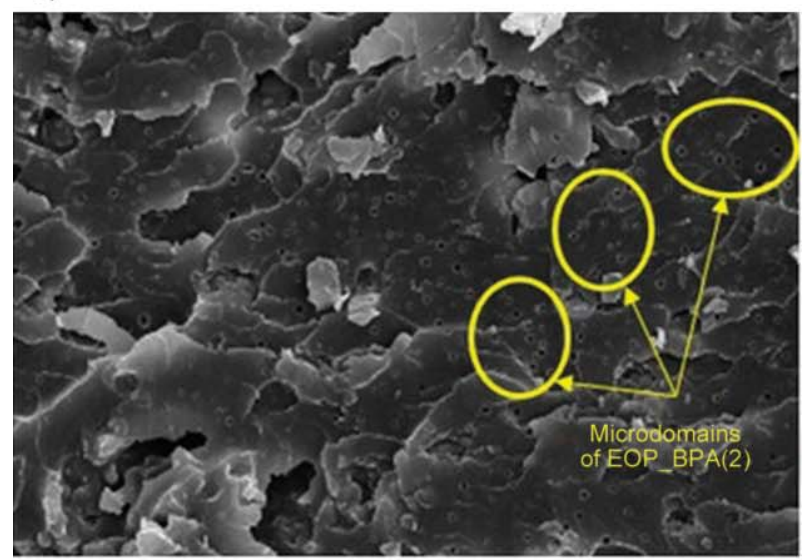

c)

Figure 11. SEM micrographs of the impact fracture surface of crosslinked: a) unmodified EPR 0162 and compositions containing $10 \mathrm{wt} \%$ of: b) EOP_BPA(1) and c) EOP_BPA(2).

the hydroxyl number of the product EOP-4 was the lowest of the others $\left(H V_{\mathrm{EOP}-4}=26.57 \mathrm{mg} \mathrm{KOH} / \mathrm{g}\right)$.

In the next stage, the polyaddition products were obtained by the reaction of epoxidized palm oil (EOP) and bisphenol A (BPA), using the epoxy fusion process. On the basis of the performed studies, using analysis of the content of functional groups, FT-IR, GPC, ${ }^{1} \mathrm{H}$ NMR, and ${ }^{13} \mathrm{C}$ NMR, the chemical structure 
of all obtained palm oil derivatives were determined. It was found that during the polyaddition process initially, after the reaction of the oxirane group of EOP with the hydroxyl group of BPA, subsequent reactions occurred, involving the reaction of a free phenolic group with the following macromolecule of modified oil. Finally, based on modified palm oil, it was possible to obtain new epoxy-polyurethane materials with interesting properties, as well as use obtained palm oil derivatives as a modifier for bisphenol A-based epoxy resins. Epoxy-polyurethane materials obtained through the reaction with 4,4'methylenebis(phenyl isocyanate) are characterized by differential mechanical properties, which depend on the properties of the polyaddition product. In turn, the modifier, despite the fact that it is only a physical additive, increases the flexibility and impact strength of the usually stiff and brittle epoxy composition without significantly deteriorating other strength properties. Furthermore, due to the controversy which has arisen in recent years regarding the use of palm oil for food purposes, the results of the carried out studies may indicate a new direction of the use of this interesting raw material.

\section{References}

[1] Zhu Y., Romain C., Williams C. K.: Sustainable polymers from renewable resources. Nature, 540, 354-362 (2016).

https://doi.org/10.1038/nature21001

[2] Zhang C., Garrison T. F., Madbouly S. A., Kessler M. R.: Recent advances in vegetable oil-based polymers and their composites. Progress in Polymer Science, 71, 91-143 (2017).

https://doi.org/10.1016/j.progpolymsci.2016.12.009

[3] Acar M., Çoban S., Hazer B.: Novel water soluble soya oil polymer from oxidized soya oil polymer and diethanol amine. Journal of Macromolecular Science Part A: Pure and Applied Chemistry, 50, 287-296 (2013). https://doi.org/10.1080/10601325.2013.755443

[4] Samarth N. B., Mahanwar P. A.: Modified vegetable oil based additives as a future polymeric material - Review. Open Journal of Organic Polymer Materials, 5, 1-22 (2015).

https://doi.org/10.4236/ojopm.2015.51001

[5] Fitzherbert E. B., Struebig M. J., Morel A., Danielsen F., Brühl C. A., Donald P. F., Phalan B.: How will oil palm expansion affect biodiversity? Trends in Ecology and Evolution, 23, 538-545 (2008).

https://doi.org/10.1016/j.tree.2008.06.012
[6] Azhar B., Saadun N., Prideaux M., Lindenmayer D. B.: The global palm oil sector must change to save biodiversity and improve food security in the tropics. Journal of Environmental Management, 203, 457-466 (2017). https://doi.org/10.1016/j.jenvman.2017.08.021

[7] Oosterveer P.: Promoting sustainable palm oil: Viewed from a global networks and flows perspective. Journal of Cleaner Production, 107, 146-153 (2015). https://doi.org/10.1016/j.jclepro.2014.01.019

[8] Ang D. T-C., Khong Y. K., Gan S. N.: Palm oil-based compound as environmentally friendly plasticizer for poly(vinyl chloride). Journal of Vinyl and Additive Technology, 22, 80-87 (2016).

https://doi.org/10.1002/vnl.21434

[9] Chuayjuljit S., Sangpakdee T., Saravari O.: Processing and properties of palm oil-based rigid polyurethane foam. Journal of Metals, Materials and Minerals, 17, 17-23 (2017).

[10] Arniza M. Z., Hoong S. S., Idris Z., Yeong S. K., Hassan H. A., Din A. K., Choo Y. M.: Synthesis of transesterified palm olein-based polyol and rigid polyurethanes from this polyol. Journal of the American Oil Chemists' Society, 92, 243-255 (2015).

https://doi.org/10.1007/s11746-015-2592-9

[11] Lee C. S., Ooi T. L., Chuah C. H., Ahmad S.: Rigid polyurethane foam production from palm oil-based epoxidized diethanolamides. Journal of the American Oil Chemists' Society, 84, 1161-1167 (2007). https://doi.org/10.1007/s11746-007-1150-5

[12] Park S-J., Jin F-L.: Synthesis and characterization of UV-curable acrylic resin containing fluorine groups. Polymer International, 54, 705-709 (2005). https://doi.org/10.1002/pi.1755

[13] Cheong M. Y., Ooi T. L., Ahmad S., Yunus W. M. Z. W., Kuang D.: Synthesis and characterization of palmbased resin for UV coating. Journal of Applied Polymer Science, 111, 2353-2361 (2009). https://doi.org/10.1002/app.29257

[14] Lai C-M., Rozman H. D., Tay G-S.: Palm oil-based unsaturated polyester: Activation energy and swelling properties. Polymer Engineering and Science, 53, 11381145 (2013). https://doi.org/10.1002/pen.23367

[15] Wan Rosli W. D., Kumar R. N., Zah S. M., Hilmi M. M.: UV radiation curing of epoxidized palm oil-cycloaliphatic diepoxide system induced by cationic photoinitiators for surface coatings. European Polymer Journal, 39, 593-600 (2003). https://doi.org/10.1016/S0014-3057(02)00241-0

[16] Norhaizan M. E., Hosseini S., Gangadaran S., Lee S. T., Kapourchali F. R., Moghadasian M. H.: Palm oil: Features and applications. Lipid Technology, 25, 39-42 (2013). https://doi.org/10.1002/lite.201300254 
[17] Edem D. O.: Palm oil: Biochemical, physiological, nutritional, hematological and toxicological aspects: A review. Plant Foods for Human Nutrition, 57, 319-341 (2002). https://doi.org/10.1023/A:1021828132707

[18] Mukherjee S., Mitra A.: Health effects of palm oil. Journal of Human Ecology, 26, 197-203 (2009). https://doi.org/10.1080/09709274.2009.11906182

[19] Mancini A., Imperlini E., Nigro E., Montagnese C., Daniele A., Orrù S., Buono P.: Biological and nutritional properties of palm oil and palmitic acid: Effects on health. Molecules, 20, 17339-17361 (2015). https://doi.org/10.3390/molecules200917339

[20] Aguiar L. K., Martinez D. C., Caleman S. M. Q.: Consumer awareness of palm oil as an ingredient in food and non-food products. Journal of Food Products Marketing, 24, 297-310 (2017). https://doi.org/10.1080/10454446.2017.1266559

[21] Chowdhury K., Banu L. A., Khan S., Latif A.: Studies on the fatty acid composition of edible oil. Bangladesh Journal of Scientific and Industrial Research, 42, 311316 (2007).

https://doi.org/10.3329/bjsir.v42i3.669

[22] Keleş E., Hazer B.: Synthesis of segmented polyurethane based on polymeric soybean oil polyol and poly (ethylene glycol). Journal of Polymers and the Environment, 17, 153-158 (2009).

https://doi.org/10.1007/s10924-009-0132-0

[23] Czub P., Franek I.: Epoxy resins modified with palm oil derivatives - Preparation and properties. Polimery, 58, 135-139 (2013). https://oi.org/10.14314/polimery.2013.135

[24] Sienkiewicz A., Czub P.: Synthesis of high-molecular weight biobased epoxy resins: Determination of the course of the process by MALDI-TOF mass spectrometry. ACS Sustainable Chemistry and Engineering, 6, 6084-6093 (2018).

https://doi.org/10.1021/acssuschemeng.7b04727

[25] Sienkiewicz A., Czub P.: Application of MALDI-TOF, ${ }^{1} \mathrm{H}$ NMR and ${ }^{13} \mathrm{C}$ NMR to follow the progress of the synthesis of high molecular weight epoxies from hydroxylated soybean oil and bisphenol A based epoxy resin. Polymer Testing, 73, 200-207 (2019). https://doi.org/10.1016/j.polymertesting.2018.11.015

[26] Czub P.: Synthesis of high-molecular-weight epoxy resins from modified natural oils and Bisphenol A or Bisphenol A-based epoxy resins. Polymers for Advanced Technologies, 20, 194-208 (2009).

https://doi.org/10.1002/pat.1252
[27] Saurabh T., Patnaik M., Bhagt S. L., Renge V. C.: Epoxidation of vegetable oils: A review. International Journal of Advanced Engineering Technology, 2, 491-501 (2011).

[28] Chua S-C., Xu X., Guo Z.: Emerging sustainable technology for epoxidation directed toward plant oil-based plasticizers. Process Biochemistry, 47, 1439-1451 (2012).

https://doi.org/10.1016/j.procbio.2012.05.025

[29] Armylisas A. N., Hazirah M. S., Yeong S. K., Hazimah A. H.: Modification of olefinic double bonds of unsaturated fatty acids and other vegetable oil derivatives via epoxidation: A review. Grasas y Aceites, 68, 174/1174/11 (2017). https://doi.org/10.3989/gya.0684161

[30] Du H., Zhao Y., Li Q., Wang J., Kang M., Wang X., Xiang H.: Synthesis and characterization of waterborne polyurethane adhesive from MDI and HDI. Journal of Applied Polymer Science, 110, 1396-1402 (2008). https://doi.org/10.1002/app.28805

[31] Sun D., An J., Wu G., Yang J.: Double-layered reactive microcapsules with excellent thermal and non-polar solvent resistance for self-healing coatings. Journal of Materials Chemistry A, 3, 4435-4444 (2015). https://doi.org/10.1039/C4TA05339G

[32] Sienkiewicz A., Czub P.: Novel bio-based epoxy-polyurethane materials from modified vegetable oils - Synthesis and characterization. Express Polymer Letters, 11, 308-319 (2017).

https://doi.org/10.3144/expresspolymlett.2017.30

[33] Sienkiewicz A., Czub P.: Blocked isocyanates as alternative curing agents for epoxy-polyurethane resins based on modified vegetable oils. Express Polymer Letters, 13, 642-655 (2019). https://doi.org/10.3144/expresspolymlett.2019.54

[34] Norhisham S. M., Maznee T. T. N., Ain H. N., Devi P. K., Srihanum A., Norhayati M. N., Yeong S. K., Hazimah A. H., Schiffman Ch. M., Sendijarevic A., Sendijarevic V., Sendijarevic I.: Soft polyurethane elastomers with adhesion properties based on palm olein and palm oil fatty acid methyl ester polyols. International Journal of Adhesion and Adhesives, 73, 38-44 (2017). https://doi.org/10.1016/j.ijadhadh.2016.10.012

[35] Sarwono A., Man Z., Bustam M. A.: Blending of epoxidised palm oil with epoxy resin: The effect on morphology, thermal and mechanical properties. Journal of Polymers and the Environment, 20, 540-549 (2012). https://doi.org/10.1007/s10924-012-0418-5 